\title{
BMJ Open Lifelong bound feet in China: a quantitative ultrasound and lifestyle questionnaire study in postmenopausal women
}

\author{
Ling Qin, ${ }^{1}$ Yi Pan, ${ }^{2}$ Ming Zhang, ${ }^{3}$ Mian $X u,{ }^{2}$ Hanchang Lao, ${ }^{4}$ Michael C O'Laughlin, \\ Shan Tong, ${ }^{3}$ Yanling Zhao, ${ }^{5}$ VWY Hung, ${ }^{1}$ JCY Cheng, ${ }^{1}$ Xia Guo ${ }^{6}$
}

To cite: Qin L, Pan Y, Zhang $\mathrm{M}$, et al. Lifelong bound feet in China: a quantitative ultrasound and lifestyle questionnaire study in postmenopausal women. BMJ Open 2015;5:e006521. doi:10.1136/bmjopen-2014006521

- Prepublication history and additional material is available. To view please visit the journal (http://dx.doi.org/ 10.1136/bmjopen-2014006521)

$L Q$ and $Y P$ are joint first authors.

Received 15 September 2014 Revised 28 January 2015 Accepted 12 February 2015

CrossMark

For numbered affiliations see end of article.

\section{Correspondence to} Professor Ling Qin (for study design and implementation); lingqin@cuhk.edu.hk;

Professor Ming Zhang (for gait analysis); ming.zhang@ polyu.edu.hk; Professor Xia Guo (for balance evaluation) xia.guo@polyu.edu.hk

\section{ABSTRACT}

Objective: The phenomenon of foot binding, also known as 'lotus feet', has an enduring and influential history in China. To achieve a man-made smaller foot size, lifelong foot binding may have had adverse effects on the skeleton. We investigated bone properties in postmenopausal women with bound feet, which may provide new information for developing countermeasures for prevention of fragility fractures.

Design: Population-based cohort study.

Participants: This study involved 254 postmenopausal women aged 65-80, including 172 with bound feet and 82 age- and gender-matched control subjects, living in a remote region of China. Outcomes: Anthropometric, SF-36 Lifestyle Questionnaire and heel quantitative ultrasound (QUS) data were collected for the whole study population. A small subset of two cases was also invited for assessment of bone mineral density and microarchitecture at the distal tibia using highresolution peripheral quantitative CT (HR-pQCT) and gait and balance tests.

Results: Women with bound feet had significantly lower QUS values than age-matched women with normal feet; this was supported by HR-pQCT data. However, SF-36 Questionnaire results did not reveal any statistically significant differences in any categorical responses, including physical functioning, general health vitality and physical component summary score, and number of previous fractures. No impairment of body balance was found in the small subset.

Conclusions: The man-made changes caused by foot binding led to reduced physical activity, making the subjects prone to osteoporosis. Women with bound feet and osteoporosis did not have a higher incidence of fragility fractures than controls. This might be explained by compensation in physical activity to improve body balance, implying the importance of improving or maintaining body balance in overall prevention strategies against fragility fractures.

\section{INTRODUCTION}

Few phenomena in history have been brought to such a high level of esteem and

\section{Strengths and limitations of this study}

- Population-based cohort study involving 172 postmenopausal women with bound feet.

- Conventional and advanced bone densitometry and lifestyle questionnaire.

- Clinically relevant findings.

- Improving or maintaining body balance is essential for prevention of fragility fractures.

- Cross-sectional study design.

popularity with a perplexing origin, and even fewer have shared such extensive, enduring effects. For over a millennium, Chinese women of all ages and social classes have bound their feet to a fraction of their original size, suffering great pain and hardship during the process. Literature documents that this tradition was begun in the closing years of the tenth century either by dancers during the Song dynasty, which valued the aesthetic beauty and graceful movements of small feet, or a hedonistic emperor, who ordered his concubines to bind their feet to resemble the shape of a 'golden lotus' leaf. $^{12}$ One aspect beyond debate, however, is the widespread influence of foot binding and the longevity of its practice: spanning over 1000 years and four dynasties in China. The tradition reached its apex during the 18 th century, when over $50 \%$ of all women and close to $100 \%$ of women in upper class societies bound their feet. ${ }^{23}$

Foot binding was first outlawed in 1912, but persisted in various rural regions of China. Women with small feet were associated with restricted labour and physical activity, which promoted feminine behaviour and increased their likelihood of marriage. ${ }^{1-3}$ Women aged 65 or above have now become the last generation still living with bound feet. These women mainly reside in rural and impoverished 
provinces of China. However, while the phenomenon is well documented, very few reports have collected scientific data to study the direct effect of lifelong foot binding on bone status and fragility fractures.

One of the observable consequences of lifelong foot binding is the reduced size of the foot and the accordingly significant decrease in support area (figure 1), which greatly hinders ability to participate in both social and physical activities throughout life. There is strong evidence that physical exercise enhances bone health. ${ }^{4-7}$ The decreased support resulting from the smaller foot area would be likely to reduce balancing capability, leading to a greater risk of falling, and increase the incidence of fragility fracture due to restricted physical activity ${ }^{7-9}$ We therefore hypothesised that women with bound feet would have adverse effects on musculoskeletal health due to diminished lifelong physical activity, decreased ability to balance as a result of a smaller foot support area, and therefore higher fall frequency and fall-related fragility fractures.

\section{METHODS}

\section{Participants}

This was a project conducted by clinical scientists and bioengineers from Hong Kong and physicians from Mainland China to reveal the social and physiological effects of lifelong foot binding, with participants recruited from Luliang County of Yunnan Province, China (see online supplement 1). Participants who had any diseases or drug use known to affect metabolism of the musculoskeletal system or a recent fracture (within 1 year) were excluded. The study was supported by the Chinese Health Promotion Foundation, and human ethics approval was obtained from the Second Affiliated Hospital of Kunming Medical College for the part of the study conducted in Kunming and the Chinese University of Hong Kong for the part conducted in Hong Kong.

A total of 254 subjects were included in the study: 172 had bound feet (mean \pm SD age $74.6 \pm 3.5$ years, range 65-80) and 82 had normal feet (mean age 74.5 \pm 4.0 years, range 69-87). All subjects had their weight and height measured and body mass index (BMI) calculated. History of fractures, number of children and years since menopause (YSM) were also documented.

A modified 36-item Short Form Health Survey (SF-36) was given to all participants after translation into Chinese that had been validated by one of our previous studies. ${ }^{10}$ The survey was organised into eight multi-item scales assessing physical functioning $(\mathrm{PF})$, physical role $(\mathrm{PR})$, bodily pain $(\mathrm{BP})$, general health $(\mathrm{GH})$, vitality (VT), social functioning (SF) and emotional role (ER) in daily activities and mental health $(\mathrm{MH})$, which comprehensively determine the quality of life and physical, mental and psychosocial health (see online Appendix). Of the eight categories, the five that govern physical well-being of (PF, PR, BP, GH and VT) were linearly transformed to a $0-100$ scale using a standardised threestep algorithm and subsequently scaled by computing the mean values for each category. ${ }^{11}{ }^{12}$ Mean values for each variable were compared between the two groups to

Figure 1 A side-by-side aerial view drawing showing the physical difference between normal feet $(A)$ and bound feet (B). Lateral X-ray images comparing a normal foot $(C)$ and a bound foot (D) in postmenopausal women.
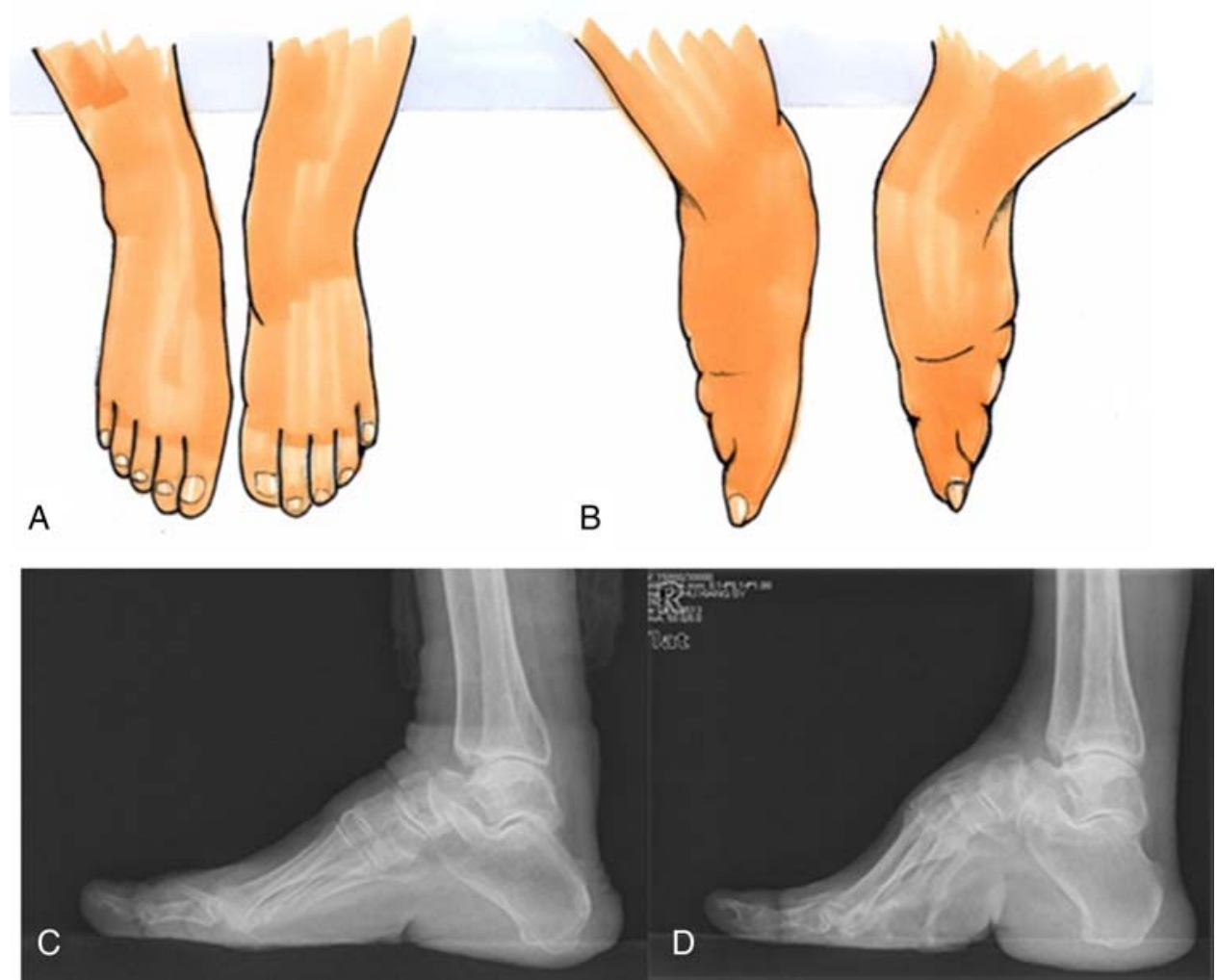
determine differences between subjects with bound feet and controls. Finally, scaled scores in each category were combined to produce a higher-order physical component summary (PCS) score. The PCS score was standardised with the 1998 US general population database with a mean score of 50 and SD of $10 .{ }^{13}$

\section{Heel quantitative ultrasound}

All 254 recruited subjects participated in quantitative ultrasound (QUS) evaluation of the heel in Luliang County using a Lunar Achilles Plus (GE Healthcare, Milwaukee, Wisconsin, USA) (figure 2). Speed of sound (SOS; m/s) and broadband ultrasound attenuation (BUA; $\mathrm{Db} / \mathrm{MHz}$ $\mathrm{cm}$ ) were recorded. A Stiffness Index (SI) was derived from SOS and BUA based on the following formula: $\mathrm{SI}=(0.67 \times \mathrm{BUA})+(0.28 \times \mathrm{SOS})-420 .{ }^{14}$ QUS T-scores were calculated using a built-in Chinese female reference population. Z-values were subsequently calculated with the same formula, expressed as SD above or below the mean SI values of an age-, gender- and weight-matched reference database. Instead of a conventional T-score $\leq-2.5$ $\mathrm{SD}$, a T-score $\leq-1.8 \mathrm{SD}$ was used as the cut-off value for defining osteoporosis, as previous studies demonstrated that the T-score threshold of $-2.5 \mathrm{SD}$ might lead to underestimation of the prevalence of osteoporosis when QUS was used for bone measurement at the heel, ${ }^{15}{ }^{16}$ while a QUS T-score threshold of $-1.8 \mathrm{SD}$ identified the same percentage of people with osteoporosis as the WHO threshold for bone mineral density (BMD) measurements using dual-energy X-ray absorptiometry. ${ }^{16} 17$

Owing to the large physical distance between Luliang County and Hong Kong (see online supplement 1) and as we lacked financial support for international travel, only two women with bound feet with mean QUS values representative of the bound feet group were invited to Hong Kong for case analysis using advanced

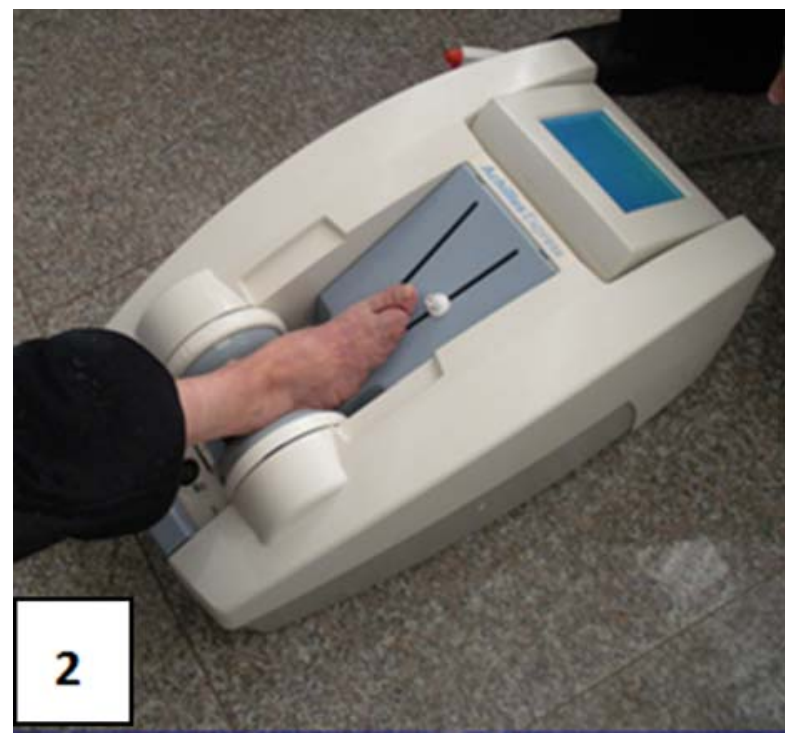

Figure 2 Heel quantitative ultrasound measurement in a woman with bound feet. assessments: three-dimensional bone densitometry (see online supplement 2) and relevant gait and body balance analysis tests for predicting falls and fragility fractures (see online supplement 3 ).

\section{Statistical analysis}

We used SPSS for Windows V.19.0 for statistical analysis. Quantitative data were expressed as mean \pm SD for continuous data and counts by percentage for discrete data. Student's $\mathrm{t}$ test was used to compare the following variables between the two groups: age, BMI, size of foot, centre of gravity, number of children, YSM, previous fractures, and rate of T-score-based osteoporosis. The $\chi^{2}$ test was used to determine the association between previous fracture rate and bound feet status and between T-score of QUS data and bound feet status. For SF-36 Questionnaire data, we used Student's t test to determine if statistical significance existed between categorical mean values of subjects. The $\chi^{2}$ test was used to assess statistical difference in rate of osteoporosis and incidence of low-energy fractures between the two groups. Values of $\mathrm{p}<0.05$ were considered significant.

\section{RESULTS}

\section{Anthropometric data and SF-36 Questionnaire}

Table 1 shows no statistically significant difference in age between postmenopausal women with and without bound feet, implying a homogeneous grouping for comparison. Significant differences were, however, seen in body weight, BMI, length and width of feet, number of children, and T-score-based rate of osteoporosis between the two groups. SF-36 Questionnaire results are summarised in table 2: no statistically significant differences were found in any categorical responses between women with and without bound feet except the VT score, which shows a noticeable but not statistically significant decrease in the subjects with bound feet.

\section{Heel QUS}

Figure 3 shows T- and Z-scores of heel QUS bone SI. The mean T- and Z-scores of women with bound feet are both significantly lower than that of the age- and gender-matched control subjects $(\mathrm{p}<0.01$ for both) (figure 3). The T-score-based calculation shows $32.51 \%$ more osteoporotic cases found in women with bound feet $(165 / 172$, ie, $95.93 \%)$ than in age- and gendermatched control subjects $(52 / 82$, ie, $63.42 \%)(p<0.01)$.

\section{DISCUSSION}

Lifelong foot binding is a widespread tradition in ancient China, which still affects a significant number of older women living in rural regions. We investigated potential adverse effects of foot binding on the musculoskeletal system, including bone mineral and structural status along with major fracture risk factors and fracture incidence. Our findings confirmed our hypothesis that women with bound feet had adverse effects on bone 
Table 1 Anthropometric and lifestyle data compared between women with or without bound feet

\begin{tabular}{|c|c|c|c|c|}
\hline Variable & Bound feet $(\mathrm{N}=172)$ & Controls $(\mathrm{N}=82)$ & Difference (\%) & p Value \\
\hline \multicolumn{5}{|l|}{ Anthropometric } \\
\hline Age (years) & $74.6 \pm 3.5$ & $74.5 \pm 4.0$ & $0.20 \%$ & 0.756 \\
\hline Weight (kg) & $46.1 \pm 7.4$ & $48.7 \pm 8.9$ & $-5.3 \%$ & $0.017^{\star}$ \\
\hline BMI $\left(\mathrm{kg} / \mathrm{m}^{2}\right)$ & $20.8 \pm 3.2$ & $21.9 \pm 3.5$ & $-5.1 \%$ & $0.013^{*}$ \\
\hline Length of right foot $(\mathrm{cm})$ & $222.7 \pm 18.4$ & $254.0 \pm 7.3$ & $-12.3 \%$ & $0.000^{* *}$ \\
\hline Width of right foot $(\mathrm{cm})$ & $74.3 \pm 8.4$ & $99.8 \pm 7.0$ & $-25.6 \%$ & $0.000^{* *}$ \\
\hline \multicolumn{5}{|l|}{ Lifestyle } \\
\hline YSM & $26.41 \pm 5.21$ & $27.49 \pm 5.98$ & $3.93 \%$ & 0.142 \\
\hline Number of children & $7.02 \pm 2.63$ & $6.21 \pm 2.13$ & $13.00 \%$ & $0.007^{\star \star}$ \\
\hline Number of subjects with previous fractures & $13 / 172(7.56)$ & $6 / 82(7.30)$ & $0.26 \% \ddagger$ & 0.846 \\
\hline Osteoporosis (QUS-SI)† & $165 / 172(95.93)$ & $52 / 82(63.42)$ & $32.51 \% \S$ & $0.000^{\star *}$ \\
\hline \multicolumn{5}{|l|}{ OR } \\
\hline \multicolumn{5}{|c|}{$\begin{array}{l}\text { Values are mean } \pm \text { SD or } n / N(\%) \\
{ }^{*} p<0.05,{ }^{* *} p<0.01 \text { (unpaired } t \text { test). } \\
\text { †T-score set at }-1.8 \text { SD and } \chi^{2} \text { test used for statistical analysis. } \\
\text { †OR }=1.036(p>0.05) \text {. } \\
\text { §OR }=13.60(p<0.01) \text {. }\end{array}$} \\
\hline
\end{tabular}

health, but disproved our concerns about osteoporosisassociated increases in fragility fractures.

Owing to availability, we only used a portable heel QUS for bone scans in Luliang County, a remote mountain area of Kunming Province to quantify bone status of 172 postmenopausal women with bound feet and their peers. However, calcaneus bone is a skeletal site that is directly affected by foot binding and associated alterations in physical activity. Our QUS measurements showed a rate of osteoporosis that was one-third higher in women with bound feet than in the controls. High-resolution peripheral quantitative CT (HR-pQCT) used for a small subset evaluation in the present study is an advanced technology that allows insight into volumetric BMD (vBMD) and microarchitecture. Trabecular microarchitecture variables for the representative subjects indicated that bone quality was inferior in women with bound feet, with on average a $20 \%$ lower trabecular number and $42.7 \%$ of vBMD in the core region of the distal tibia, although the cortical vBMD was much less affected, with only $18.1 \%$ lower mean value compared with the age- and gender-matched reference population

Table 2 Descriptive statistics of five scaled categories used to assess physical health in the SF-36 Questionnaire

\begin{tabular}{llll}
\hline Category & $\begin{array}{l}\text { Bound feet } \\
(\mathrm{N}=172)\end{array}$ & $\begin{array}{l}\text { Controls } \\
\mathbf{( N = 8 2 )}\end{array}$ & p Value \\
\hline $\begin{array}{l}\text { Physical } \\
\text { functioning }\end{array}$ & $65.40 \pm 22.54$ & $67.53 \pm 24.03$ & 0.494 \\
Physical role & $45.76 \pm 41.24$ & $47.81 \pm 40.41$ & 0.712 \\
Bodily pain & $64.05 \pm 22.53$ & $61.75 \pm 21.86$ & 0.448 \\
General health & $56.65 \pm 18.41$ & $54.69 \pm 22.40$ & 0.495 \\
Vitality & $61.32 \pm 15.01$ & $64.81 \pm 15.44$ & 0.090 \\
PCS score & 42.9 & 42.4 & \\
\hline
\end{tabular}

Values are mean $\pm S D$

PCS, physical component summary. database (see online supplement 2), implying a systemic adverse effect of foot binding on weight-bearing bones. If such a difference is independent of weight bearing, measurements at non-weight-bearing skeletal sites, such as the distal radius, in a sizeable subgroup in future studies might provide evidence to support this hypothesis.

Previous QUS studies in normal postmenopausal women show the QUS value for evaluation of osteoporosis and predicting fragility fractures. ${ }^{17-20}$ As fragility fractures can be associated with both skeletal and nonskeletal factors, we used the SF-36 Questionnaire, a validated instrument for evaluating the relationship between physical activity and osteoporosis and/or fragility fractures, in this study. ${ }^{13}{ }^{21}$ Impaired balance is a known risk factor for fall-associated fragility fractures in women with normal feet. ${ }^{8} 22{ }^{23}$ However, our analysis only showed non-detectable inferior VT and PF in women with bound feet and differences in accumulated plantar pressure, with more pressure placed on the calcaneus of the heel and less force distributed over the forefoot in bound feet (see online supplement 2), implying a compensation mechanism in human kinesiology after foot binding in later life. Our data did not show any difference in number of previous fractures in women with or without foot binding.

In 1997, Cummings and coworkers reported the first dual-energy X-ray absorptiometry study to measure BMD at the spine and hip in postmenopausal women with bound feet in Beijing, the capital of China, and reported that lifelong foot binding had significant adverse effects on spine BMD, and the fragility fracture rate was higher than in control subjects. ${ }^{24}$ The direct adverse effect to the bound feet is the significantly reduced foot size, which is described as 'golden lotus'. The consequence is an increased tendency to fall and an increased risk of fall-induced fractures in later life. The overall higher 


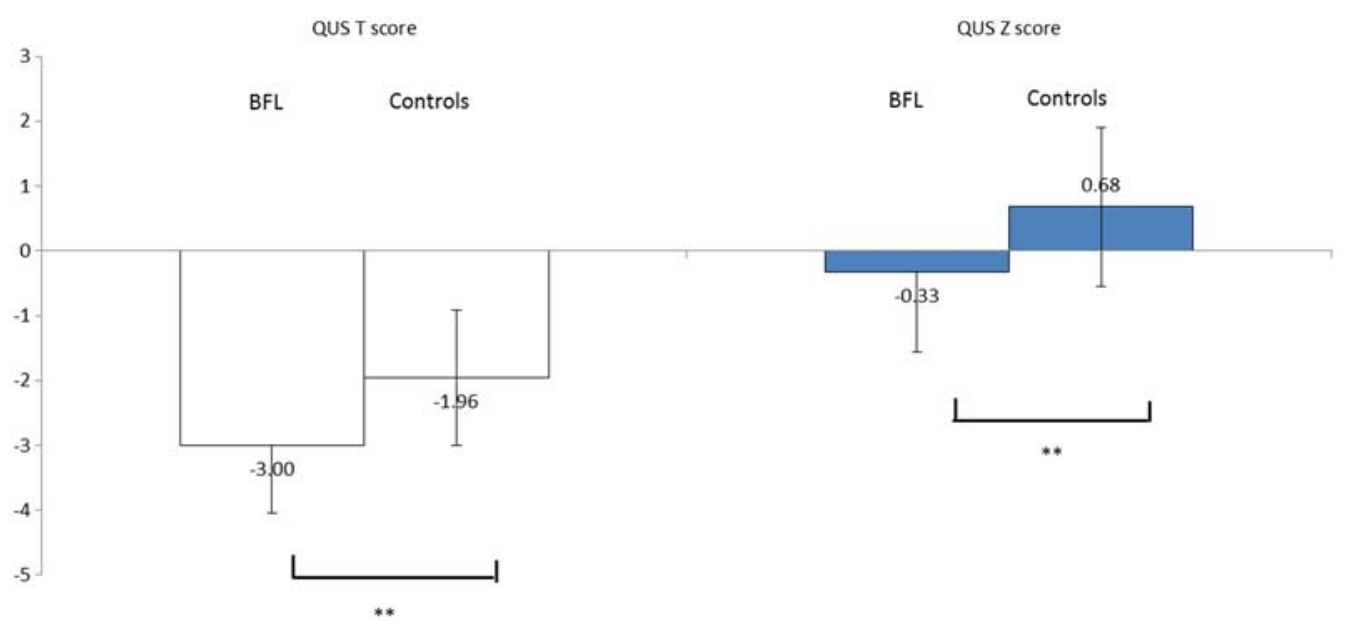

Figure 3 Quantitative ultrasound (QUS) calcaneal bone Stiffness Index-based T- and Z-scores of 'bound feet ladies' (BFL; $n=172)$ compared with the controls $(n=82) .{ }^{* *} p<0.01$.

fracture rate in the Beijing study was $15 \%$, while a significantly lower fracture incidence of $7.5 \%$ was found in our subjects, which might be explained by different lifestyles between women living in urban areas such as Beijing in the study of Cummings $e t a l^{4}$ and those living in rural regions such as Luliang, a remote county in Yunnan Province. There were no balance and gait data available in the Beijing study. The subjects with bound feet in that study were mostly descendants of upper class families, and little physical work was required in their later life, with impairment in musculoskeletal coordination speculated to explain both higher osteoporosis- and fall-associated fragility fracture rates. ${ }^{1} 32425$ The fact that our study subjects in remote Luliang County were working class women who often had to perform manual labour in old age might explain why the balance analysis and lifestyle questionnaire did not show any differences between women with and without bound feet evaluated in a small subset of subjects (see online supplement 3 ). The associated active lifestyle might have led to different adaptations to achieve body balance throughout life to compensate for the smaller foot support area.

The findings of our study on heel QUS and lifestyle in terms of the SF-36 Questionnaire offer a unique insight into the effects of foot binding. The significance of our study to social and healthcare aspects was the mobilisation of the local government to support our project. The findings generated from our study have raised awareness of osteoporosis-prevention measures in rural regions of China at more than one site. Apart from differences in nutrition, ${ }^{26}{ }^{27}$ the importance of physical activity and/or exercise is specifically relevant for maintenance of balance, and this has been known to be a crucial factor for prevention of falls and fall-induced fragility fractures. 7102829

Our study had a few limitations in addition to its crosssectional nature: (1) non-homogeneous number of study subjects-the higher percentage of women with bound feet was due to a greater percentage of older women with bound feet living in the study location; (2) owing to a limited budget and the long distance between remote Luliang County and Hong Kong, only a few subjects were invited to fly to Hong Kong for HR-pQCT and gait and balance tests (see online supplements 2 and 3); (3) as only recall was used to obtain fracture history, no reliable fall frequency could be provided for analysis.

\section{CONCLUSION}

Foot binding had a lifelong negative impact on bone health. However, the neuromusculoskeletal coordination of the postmenopausal women with bound feet who had an active lifestyle might have compensated for the negative effects, as no difference was found in incidence of fragility fractures, implying the importance of maintenance of body balance in prevention of fragility fractures.

\section{Author affiliations}

${ }^{1}$ Department of Orthopaedics and Traumatology, Bone Quality and Health Centre, The Chinese University of Hong Kong, Hong Kong, Hong Kong

${ }^{2}$ Department of Endocrinology, The Second Affiliated Hospital of Kunming Medical University, Kunming, Yunnan Province, China

${ }^{3}$ Department of Mechanical Engineering, The Hong Kong Polytechnic University, Hong Kong, Hong Kong

${ }^{4}$ Department of Orthopaedics, The Second Affiliated Hospital of Kunming Medical University, Kunming, Yunnan Province, China

${ }^{5}$ Training Department of International Osteoporosis Diagnosis and Treatment, Health Promotion Foundation of China, Beijing, China

${ }^{6}$ Department of Rehabilitation Sciences, The Hong Kong Polytechnic University, Hong Kong, Hong Kong

Acknowledgements We appreciate technical support from Miss TN Fong and Miss WY Hung of the Bone Quality and Health Centre, Department of Orthopaedics and Traumatology, The Chinese University of Hong Kong and their assistance with HR-pQCT measurements.

Contributors $L Q$ designed and organised the project, participated in data collection, analysis and interpretation, and supervised preparation of the manuscript; YP, MX and HL recruited subjects, performed questionnaires and conducted QUS scanning at Luliang County; MZ and ST performed gait analysis, and $X G$ performed balance tests and related analyses in Hong Kong. $Y Z$ co-organised the study and jointly applied for research grants for this project; MCO performed part of the data analysis and assisted in drafting the 
manuscript. VWYH performed the HR-pQCT measurements and associated data analysis; JCYC contributed to planning and preparation of the manuscript.

Funding This study was supported by the China Health Promotion Foundation (Ref 2009-01) and the Contemporary Orthopaedic Research and Education Fund of the Chinese University of Hong Kong (CUHK\#6903361).

Competing interests None.

Patient consent Obtained.

Ethics approval Second Affiliated Hospital of Kunming Medical College for the part of the study conducted in Kunming and the Chinese University of Hong Kong for the part conducted in Hong Kong.

Provenance and peer review Not commissioned; externally peer reviewed.

Data sharing statement The authors agree with data sharing as specified in the policy of BMJ Open to make all submitted materials, including supplementary files, available to the public.

Open Access This is an Open Access article distributed in accordance with the Creative Commons Attribution Non Commercial (CC BY-NC 4.0) license, which permits others to distribute, remix, adapt, build upon this work noncommercially, and license their derivative works on different terms, provided the original work is properly cited and the use is non-commercial. See: http:// creativecommons.org/licenses/by-nc/4.0/

\section{REFERENCES}

1. Levy HS. Chinese footbinding: the history of a curious erotic custom. New York, NY: W. Rawls, 1966.

2. Wang P. Aching for beauty: foot binding in China. Minneapolis: University of Minnesota Press, 2000.

3. Fairbank JK. The Great Chinese Revolution: 1800-1985. New York: Harper \& Row, 1986.

4. Gerdhem P, Akesson K, Obrant KJ. Effect of previous and present physical activity on bone mass in elderly women. Osteoporosis Int 2003:14:208-12.

5. Cooper C, Harvey NC. Osteoporosis risk assessment. BMJ 2012;344:e3427.

6. Qin L, Au SZ, Choy YW, et al. Regular Tai Chi exercise may retard bone loss in postmenopausal women-a case control study. Arch Phys Med Reha 2002;83:1355-9.

7. Qin L, Choy WY, Leung KS, et al. Beneficial effects of regular Tai Chi exercise on musculoskeletal system. J Bone Miner Metabol 2005;23:186-90.

8. Edwards $\mathrm{MH}$, Jameson $\mathrm{K}$, Denison $\mathrm{H}$, et al. Clinical risk factors, bone density and fall history in the prediction of incident fracture among men and women. Bone 2013:52:541-7.

9. Hippisley-Cox J, Coupland C. Derivation and validation of updated QFracture algorithm to predict risk of osteoporotic fracture in primary care in the United Kingdom: prospective open cohort study. BMJ 2012;344:e4191;1-16.

10. Chan KM, Qin L, Lau M, et al. A randomized, prospective study of the effects of Tai Chi Chun exercise on bone mineral density in postmenopausal women. Arch Phys Med Rehab 2004;85:717-22.
11. Ware JE, Sherbourne CD. The MOS 36-item short-form health survey (SF-36). I. Conceptual framework and item selection. Med Care 1992;30:473-83.

12. Ware JE, Kosinski M, Bayliss MS, et al. Comparison of methods for the scoring and statistical analysis of SF-36 health profile and summary measures: summary of results from the Medical Outcomes Study. Med Care 1995;33:264-79.

13. Maglinte GA, Hays RD, Kaplan RM. US general population norms for telephone administration of the SF-36v2. J Clin Epidemiol 2012;65:497-502

14. Economos CD, Sacheck JM, Wacker W, et al. Precision of Lunar Achilles+ bone quality measurements: time dependency and multiple machine use in field studies. Br J Radiol 2007;80:919-25.

15. Vu TT, Nguyen CK, Nguyen TL, et al. Determining the prevalence of osteoporosis and related factors using quantitative ultrasound in Vietnamese adult women. Am J Epidemiol 2005;161:824-30.

16. Frost ML, Blake GM, Fogelman I. Can the WHO criteria for diagnosing osteoporosis be applied to calcaneal quantitative ultrasound? Osteoporos Int 2000;11:321-30.

17. Liu JM, Ma LY, Bi YF, et al. A population-based study examining calcaneus quantitative ultrasound and its optimal cut-points to discriminate osteoporotic fractures among 9352 Chinese women and men. J Clin Endocrinol Metab 2012:97:800-9.

18. Hans D, Dargent-Molina P, Schott AM, et al. Ultrasonographic heel measurements to predict hip fracture in elderly women: the EPIDOS prospective study. Lancet 1996;348:511-14.

19. Glueer CC. Quantitative ultrasound techniques for the assessment of osteoporosis: expert agreement on current status. J Bone Miner Res 1997:12:1280-8.

20. Nayak S, Olkin I, Liu H, et al. Meta-analysis: accuracy of quantitative ultrasound for identifying patients with osteoporosis. Ann Intern Med 2006;144:832-41.

21. Lai BM, Tsang SW, Lam CL, et al. Validation of the Quality of Life Questionnaire of the European Foundation for Osteoporosis (QUALEFFO-31) in Chinese. Clin Rheumatol 2010;29:965-72.

22. Kanis JA. Diagnosis of osteoporosis and assessment of fracture risk Lancet 2002;359:1929-36.

23. Kern LM, Powe NR, Levine MA, et al. Association between screening for osteoporosis and the incidence of hip fracture. Ann Intern Med 2005;142:173-81.

24. Cummings $S$, Ling $X$, Stone $K$. Consequences of foot binding among older women in Beijing, China. Am J Pub Health 1997;87:1677-9.

25. US Preventive Services Task Force. Screening for osteoporosis: US preventive services task force recommendation statement. Ann Intern Med 2011;154:356-64.

26. Grigg M, Arora M, Diwan A. Role of nutritional supplementation in elderly patients with hip fractures. J Orthopaedic Translation 2014;2:26-34

27. Qin L, Choy W, Hung V, et al. Age-related vessel calcification at distal extremities is a risk factor of osteoporosis. $J$ Orthopaedic Translation 2014;2:43-8.

28. Trombetti A, Hars M, Herrmann F, et al. Effect of a multifactorial fall-and-fracture risk assessment and management program on gait and balance performances and disability in hospitalized older adults: a controlled study. Osteoporosis Int 2013:24:867-76.

29. Edwards BJ, Song J, Dunlop DD, et al. Functional decline after incident wrist fractures-Study of Osteoporotic Fractures: prospective cohort study. BMJ 2010;341:c3324. 